\title{
Pelatihan Iringan dan Teknik Garap Gejog Lesung pada Grup Seni \\ Gejog Lesung "Kumandhang"
}

\author{
Joko Tri Laksono \\ Jurusan Etnomusikologi, Fakultas Seni Pertunjukan \\ Institut Seni Indonesia Yogyakarta \\ Jalan Parangtritis Km 6,5 Yogyakarta \\ E-mail: joko_ISI@yahoo.com
}




\begin{abstract}
Abstrak
Gejog Lesung "Kumandhang" merupakan kelompok kesenian di masyarakat padukuhan Karanganom I- Ngawis-Karangmojo-Gunungkidul, yakni merupakan masyarakat yang percaya bahwa kesenian yang dimilikinya yakni Gejog Lesung tersebut telah ada sejak zaman nenek moyang mereka yang selalu difungsikan setiap upacara ulang tahun Desa maupun Rasulan. Namun, belum tersedianya instruktur profesional sesuai kompetensinya dalam kesenian Grup Seni Gejog Lesung "Kumandhang" sehingga gerak penyanyinya, iringan, maupun teknik garap penyajian terlihat sekedarnya sehingga perlu mendapat sentuhan akademisi untuk menggarap Grup Seni Gejog Lesung "Kumandhang", agar tidak monoton dan terkesan membosankan. Penyuluhan dilakukan pada 11 Maret sampai dengan 21 Agustus 2020. Peserta penyuluhan Seni Gejoglesung "Kumandhang" berjumlah 20 (duapuluh) orang peserta. Materi penyuluhan berupa modifikasi motif pukulan dan teknik garap Gejog Lesung dengan lagu Kuwi Apa Kuwi, Suwe Ora Jamu, dan Swara Suling dengan metode ceramah, demonstrasi, dan latihan. Hasil penyuluhan adalah peserta paham bagianbagian dalam sajian motif pukulan untuk Introduksi, Interlude dan Coda pada sebuah lagu, mengerti pentingnya aransemen dalam sebuah lagu, mengenal dinamika dan permainan tempo dalam garap pada sebuah ansambel Selain itu, pementasan jauh lebih hidup dan dinamis terutama lagu-lagu yang disajikan telah diaransemen, karena adanya tekhnik penggarapan dalam beberapa komposisi lagu sehingga tidak monoton dan membosankan. Pemahaman pentingnya manajemen terbuka dalam sebuah kelompok juga didapatkan dari penyuluhan ini.
\end{abstract}

Kata kunci: Gejog Lesung, iringan, garap

\title{
Accompaniment and Garap Gejog Lesung Technique Training to Gejog Lesung Art Community "Kumandhang"
}

\begin{abstract}
Gejog Lesung "Kumandhang" is an art group in the Karanganom I Ngawis Karangmojo Gunungkidul community, namely people who believe that the art they have, namely Gejog Lesung, has existed since the time of their ancestors, which has always been used every Village and Rasulan birthday ceremony. However, the unavailability of professional instructors according to their competence in the art of the Gejog Lesung Art Group "Kumandhang" so that the movements of the singers, accompaniments, and presentation techniques look modest, so it is necessary to get a touch from academics to work on the Gejog Lesung Art Group "Kumandhang", so as not to be monotonous and seem boring. The counseling was held on March 11 to August 21, 2020. There were 20 (twenty) participants of the "Kumandhang" Gejoglesung art extension. The counseling material was in the form of modification of the punch motif and the technique of working on Gejog Lesung with the songs Kuwi Apa Kuwi, Suwe Ora Jamu, and Swara Suling using lecture, demonstration, and exercise methods. The result of the counseling is that the participants understand the parts of the punch motive presentation for the Introductions, Interlude and Coda in a song, understood the importance of arrangements in a song, recognized the dynamics and tempo play in working on an ensemble., the performance is much more lively and dynamic, especially the songs presented have been arranged, because of the cultivation techniques in several song compositions so that they are not monotonous and boring. An understanding of the importance of open management in a group was also obtained from this counseling.
\end{abstract}

Keyword: Gejog Lesung, accompaniment, gara 


\section{PENDAHULUAN}

Seiring dengan perkembangan zaman, kesenian yang semula bersifat tradisi ini lambat laun menjadi berubah. Berubah dalam pengertian terutama format yang disajikan. Gejog Lesung semula hanya merupakan permainan ritmis yang monoton, namun dewasa ini dengan diselenggarakan festival dikemas menjadi sajian yang lebih menarik. Penyanyi juga menggunakan gerak tarian, sehingga menambah cantik dalam penampilannya. Tugas seniman memang berusaha untuk memenuhi permintaan masyarakat, tetapi sebagai seniman tradisi akan sangat berat untuk dapat menyesuaikan diri. Demikian pula dengan kesenian rakyat seperti halnya Seni Gejog Lesung. Makna yang terkandung dalam Kesenian Gejog Lesung lebih banyak menitikberatkan pada pola hidup masyarakat (Supriyadi, 2017). Hal itu dapat dilihat dari lagu-lagu yang dibawakan dalam penyajiannya yang mengandung anjuran tentang etika (tingkah laku) yang harus dilakukan dalam kehidupan. Oleh karena itu, perlu ada upaya khusus dibuat dalam melestarikan dan mempromosikan kesenian indonesia seperti Gejog Lesung (Rukmana et al., 2020).

Munculnya lagu-lagu dengan berbagi macam melodi, terkadang cukup mempengaruhi beberapa kesenian tradisi. Karena tidak ada pengarahan dan pembinaan sehingga mereka dengan seenaknya mengubah dan mengganti syair lagu yang sudah ada. Memang hal tersebut merupakan peluang untuk pengembangan iringan yang ada agar tidak terkesan monoton, terlebih karena pada kenyataan yang terjadi di masyarakat selaku stackholder dari kesenian rakyat tersebut mau menerima perkembangan yang terjadi. Demikian pula dengan ragam gerak tari yang ada, perlu ada pengembangan dengan memadukan berbagai unsur ragam gerak yang selaras dengan sifat dari kesenian rakyat itu sendiri. Pada setiap ada pementasan Seni Gejog Lesung "Kumandhang" selalu mendapat respon dari para penonton maupun penanggapnya, karena tidak lagi monoton baik pukulan maupun lagu lagu yang disajikannya. Berdasarkan bunyinya, Gejog Lesung adalah alat musik yang sumber bunyinya berasal dari alat musik itu sendiri atau "idiophone". Teknik pukulan lesung juga bermacammacam, sehingga menghasilkan irama unik lesung dipukul berjajar. Pertunjukan Gejog Lesung dimainkan oleh enam orang. Keunikan dari pertunjukan Gejog Lesung adalah irama yang dimainkan oleh beberapa pemain yang iramanya sebenarnya bisa dimainkan oleh satu orang (Nagara \& Machfauzia, 2020).

Masyarakat Padukuhan Karanganom I- Ngawis-Karangmojo-Gunungkidul, yakni merupakan masyarakat yang senantiasa mempertahankan dan melestarikan kebudayaan yang dimilikinya dan selalu dipercayainya. Masyarakat setempat sangat percaya bahwa kesenian yang dimilikinya yakni Gejog Lesung tersebut telah ada sejak jaman nenek moyang mereka yang selalu difungsikan setiap upacara ulangtahun Desa maupun Rasulan. Agar penyajian lebih menarik dan dapat dikategorikan sebuah pertunjukan yang layak jual, maka perlu ditata dari berbagai aspek. Pengembangan motif dan ragam gerak tari penyanyinya dengan disertai pola lantai yang sederhana, iringan termasuk setting dan penempatan instrumen dan pemusiknya serta sikap pada waktu pentas perlu mendapat sentuhansentuhan akademisi. 
Hal yang perlu mendapat perhatian dan penanganan yang khusus yakni "garap" pukulan instrumen pada penyajian sebuah lagu, sehingga tidak terkesan monoton dan membosankan. Setiap pukulan menghasilan bunyi yang berbeda-beda (Suprapto \& Kariadi, 2018). Oleh krena itu, perlu pemahaman terkait bunyi pukulan lesung dari bagian atas, samping, maupun tengahtengah atau tepat di lekukan lesung. Pembenahan memang tidak bisa secara frontal namun pelan dan pasti, karena cukup berdampak pada apa yang telah ada sehingga secara jeli dan hati-hati perlu tindakan yang bijaksana. Hal seperti di atas memang menjadi tugas dari kalangan akademisi dan sudah pada tempatnya apabila tim penyuluh LPM ISI Yogyakarta berada di lokasi dan objek kesenian Gejog Lesung dimaksud. Kesenian Gejog Lesung "Kumandhang" telah pentas beberapa kali dalam satu tahunnya. Selain pada acara malam midodareni "Rasulan" di desa Ngawis, pentas seni 17-an, juga pernah ditanggap padukuhan maupun desa di luar Ngawis.

Permasalahan yang ada yaitu: (1) Belum tersedianya instruktur profesional sesuai kompetensinya dalam kesenian Grup Seni Gejog Lesung "Kumandhang" sehingga gerak penyanyinya, iringan, maupun teknik garap penyajian terlihat sekedarnya; (2) Perlunya mendapat sentuhan akademisi untuk menggarap Grup Seni Gejog Lesung "Kumandhang", sehingga tidak monoton dan terkesan membosankan; (3) Perlu diciptakan lagu sebagai identitas Grup Gejog Lesung "Kumandhang". Oleh karena itu, pelatihan ini memberikan solusi antara lain memperkaya pola garap sajian dari motif gerak yang sudah ada untuk lebih dikembangkan, menambah perbendaharaan lagu untuk sajian pementasan, sehingga tidak terkesan monoton hanya motif gerak dan pola lantai serta iringan yang sudah ada. Manajemen yang belum tertata dengan baik dianjurkan untuk ditata dengan suatu pembukuan yang benar. Pembukuan berapa kali dan berapa jumlah nominal setiap tanggapan serta dimana pementasan dilaksanakan, diharapkan dapat mengukur secara kuantitas dan kualitas. Hal itu untuk menunjang kontinuitas dari grup dalam menghadapi dinamika perkembangan zaman.

Tidak dapat dipungkiri bahwa karya seni bisa terwujud dengan baik apabila beberapa faktor yang mendukung karya tersebut ditata dengan cermat oleh orang yang kompeten pada bidangnya. Hal tersebut merupakan sebuah tantangan ketika ada usaha untuk mengoptimalkan karya tersebut dengan memikirkan beberapa bidang disiplin seni yang bisa saling mendukung, yang pada dasarnya untuk mewujudkan sebuah karya seni itu dibutuhkan dukungan seni yang lain. Agar dukungan antar bidang seni itu bisa mencapai tingkat harmonis yang ideal, maka sangat dibutuhkan kepekaan rasa yang tinggi selain pengetahuan tentang komposisi dan penataan seni itu. Ketika seseorang dituntut untuk mengekspresikan sebuah karya melalui bidang seni yang digelutinya tentu fokus perhatian lebih pada konsep yang melatarbelakangi penciptaan karya tersebut, baru kemudian memikirkan hal-hal lain yang dapat mendukung serta menyempurnakan konsep yang ingin dicapai. Bertolak dari kenyataan itu, maka akan dilakukan sebuah usaha penataan yang bertolak pada sebuah karya seni dari bidang seni yang lain tanpa mengabaikan atau bahkan justru terfokus pada konsep yang sudah tertata. Tentu saja 
usaha ini harus dilakukan dengan bertolak pada sebuah ide dengan batasan-batasan atau frame yang melingkupinya sebagai rangsang penataan sebuah karya seni. Disinilah dibutuhkan kerjasama yang baik dalam mewujudkan idealisme konsep tersebut.

\section{METODE PENGABDIAN}

Program ini bertujuan ingin mengembangkan dan meningkatkan kelompok seni Gejoglesung "Kumandhang", khususnya kuantitas dan kualitas pertunjukannya. Permasalahan yang dimiliki oleh kelompok seni Gejoglesung "Kumandhang", yang digeluti oleh Ibu ibu muda dan remaja di Dusun Karanganom I, Desa Ngawis, Kecamatan Karangmojo Gunungkidul dapat didekati dengan suatu pola pembinaan yang lebih terfokus dalam aspek motif dan pola pukulan, terutama disesuaikan dengan "garap" lagunya. Agar penerapan penyuluhan dapat terarah dan mencapai tujuan, maka perlu pendekatan dengan metode Ceramah dan Demonstrasi, serta Pelatihan. Ketiga hal tersebut yang memudahkan para peserta penyuluhan dapat memahami dan mempelajari secara cermat dari materi yang diberikan. Diharapkan melalui pendekatan itu dapat dihasilkan suatu penyuluhan yang terarah sehingga out put-nya akan terlihat dengan baik.

\section{HASIL DAN PEMBAHASAN}

Dampak pandemi Covid-19 yang merambah di dunia bahkan Indonesia juga terimbas, yang sampai saat pencabutan Penyuluh belum berakhir. Hal ini menjadi penghalang utama dalam kegiatan tersebut.
Pertemuan yang seharusnya 12 kali tatap muka, hanya bisa berlangsung 10x tatap muka. Mengingat Desa Ngawis termasuk zona merah untuk wilayah Kecamatan Karangmojo. Namun demikian secara materi Penyuluhan telah disampaikan. Tempat kegiatan difokuskan di Sekretariat seni Gejoglesung "Kumandhang" di Balai Dusun Karanganom I, Desa Ngawis, Kecamatan Karangmojo, Kabupaten Gunungkidul. Pelaksanaan kegiatan dilaksanakan berdasarkan kesepakatan dari pertemuan pertama pada saat observasi, yakni pada hari Sabtu dan Minggu. Penyuluhan dilaksanakan pada jam 13.00 - 16.00. Waktu pelaksanaannya yang dilakukan pada 11 Maret sampai dengan 21 Agustus 2020. Peserta penyuluhan Seni Gejoglesung "Kumandhang" berjumlah 20 (dua puluh) orang peserta.

Sebelum terjun ke lapangan, penyuluh perlu mengadakan persiapan-persiapan teknis mengenai pembelajaran tentang Jathilan yang sesuai dengan kemampuan peserta. Suatu hal yang paling penting adalah menyampaikan materi tersebut dengan cara yang menarik, sehingga dapat menjadi motivasi tersendiri bagi peserta pembinaan. Dengan demikian apabila telah berada di lokasi pembinaan tidak mengalami kendala yang berarti. Karena di lapangan lokasi pembinaan telah dipersiapkan hal teknis yang berkaitan dengan tempat latihan, sarana prasarana yang ada dan masalah lain yang dibutuhkan. Mengingat terbatasnya waktu pertemuan, maka pertemuan pertama dipergunakan sebaik-baiknya dan langsung menyampaikan materi pertama seperti yang tertulis di atas. Selain itu tentu dengan penuh keakraban dan kekeluargaan memperkenalkan diri, agar tidak ada 
pembatas yang berarti. Berbekal dengan persiapan yang cukup rinci meliputi hard ware yang berupa notasi materi iringan dan lagu yang akan diajarkan, diharapkan meminimalisir hambatan dalam pelaksanaan pembinaan. Kelancaran pelaksanaan pembinaan ini juga dipengaruhi oleh kesungguhan dari semua pihak untuk mencapai tujuan pembinaan. Harapan terakhir dengan dilaksanakannya penyuluhan ini dapat memberikan pencerahan bagi masyarakat terutama yang menjadi sasaran penyuluhan, yakni seluruh anggota aktif dan pengurus grup seni Gejoglesung "Kumandhang".

Untuk kesempatan ini terfokus pada iringan (motif pukulan Lesung). Khusus iringan terutama permainan musik dan pembuatan lagu vokalnya yang relevan dengan seni Gejoglesung. Hal ini dimaksudkan agar penyuluhannya dapat dengan mudah dimengerti dan dipahami, sehingga dapat mewariskan secara tradisi kepada kelompok yang anakanak dan remaja.

Mengingat waktu yang disediakan sangat singkat sehingga harus mampu mempergunakan waktu seefisien mungkin dengan hasil yang optimal.

Kegiatan pelatihan ini dimulai dengan pengenalan pola pukulan untuk Introduksi lagu "Kuwi apa Kuwi” sebagai iringan tari dan penerapan penggarapan motif pukulan. Setelah dilakukan pengulangan, diberikan penambahan motif pukulan Interlude. Selanjutnya, pngulangan penerapan motif pukulan Introduksi dan Interlude, penambahan materi lagu "Kuwi apa Kuwi" dengan digarap suara II, dan praktek lagu "Kuwi apa Kuwi" dengan suara I dan suara II. Tahap terakhir pada lagu pertama yaitu pengenalan motif pukulan untuk coda pada lagu "Kuwi apa Kuwi" dan dilanjutkan pengulangan praktek motif pukulan untuk introduksi, interlude dan coda pada lagu "Kuwi apa Kuwi".

Materi kedua yaitu lagu "Suwe Ora Jamu” yang digarap menggunakan suara I dan II. Selanjutnya penambahan motif pukulan introduksi, interlude dan coda untuk lagu "Suwe Ora Jamu". Materi ketiga yaitu Lagu "Swara Suling" diaransemen pada suara I dan Suara II dilanjutkan praktek vokal lagu "Swara Suling" dengan menggunakan Suara I dan Suara II. Setelah itu diberikan penambahan dan penerapan motif pukulan untuk Introduksi, Interlude dan Coda pada lagu "Swara Suling". Di akhir pelatihan, ketiga lagu tersebut diulang hingga dikuasi.

Dari penjabaran di atas, materi penyuluhan yang dilaksanakan bulan Maret sampai dengan awal bulan Agustus 2020 terdiri dari beberapa bagian di antaranya: (1) Pengenalan macam-macam motif pukulan Introduksi, Interlude dan Coda dalam sebuah lagu; (2) Pengenalan teknik dan berbagai tempo serta dinamika dalam sajian sebuah ansambel; (3) Pengenalan dan Penataan Manajemen dalam sebuah organisasi; (4) Pengenalan gerak dalam bermusik (khusus untuk pemusik dan Vokalis); dan (5) Pengenalan gerak tari dengan mengikuti pola ritmis Lesung bagi Penari.

Manfaat dari pelatihan ini adalah masyarakat binaan mendapat bantuan pemikiran dan sumbangan keahlian dalam upaya meningkatkan produktivitas dan kreativitas berdasar local genius. Kuantitas dan kualitas pementasan dapat terjaga dengan baik. Sedapat mungkin manajemen 
tertata dengan benar dan profesional. Selain beberapa hal tersebut pelaksanaan program Penyuluhan Seni ini manfaat yang didapatkan yaitu masyarakat mendapat suatu masukkan yang berarti bagi perkembangan Grup Seni Gejog Lesung "Kumandhang". Melalui media tersebut masyarakat dapat mengembangkan bakat seni yang tersalurkan dengan pola pembinaan yang diberikan oleh program itu. Masyarakat juga dapat masukkan dalam segi ekonomi dengan adanya tanggapan dari penikmat seni khususnya para wisatawan yang berkunjung ke daerah tersebut maupun masyarakat pemiliknya. Melalui media tersebut masyarakat dapat mengembangkan bakat seni yang tersalurkan dengan pola pembinaan yang diberikan oleh program itu. Masyarakat juga dapat masukan dalam segi ekonomi dengan adanya tanggapan dari penikmat seni khususnya para wisatawan yang berkunjung ke daerah tersebut maupun masyarakat pemiliknya.

Indikasi yang menandakan adanya perkembangan suatu bentuk seni di masyarakat menjadikan pemerintah daerah dapat mengembangkan seni itu lebih terarah. Diharapkan dengan meningkatkan kualitas seni yang ada di masyarakat dengan program Penyuluhan Seni, pemerintah daerah mendapatkan manfaat yang positif signifikan dari peningkatan grup kesenian itu selaras dengan tujuannya, yakni menjadikan daerah wisata dengan mengoptimalkan kesenian setempat.

Kendala yang dirasakan dalam pembinaan pada program ini adalah kedisiplinan beberapa peserta peenyuluhan yang kurang tepat waktu, sesuai dengan perjanjian yang telah disepakati. Walau tidak lebih dari 30 menit. Selain itu, terpaparnya warga Desa Ngawis akibat pandemi Covid-19, mengakibatkan semua kegiatan diberhentikan termasuk program penyuluhan ini.

Hasil penyuluhan yang didapat dari program yang dilakukan selama lima bulan adalah peserta paham bagian-bagian dalam sajian motif pukulan untuk Introduksi, Interlude dan Coda pada sebuah lagu, mengerti pentingnya aransemen dalam sebuah lagu, mengenal dinamika dan permainan tempo dalam garap pada sebuah ansambel Selain itu, pementasan jauh lebih hidup dan dinamis terutama lagu-lagu yang disajikan telah diaransemen, karena adanya tekhnik penggarapan dalam beberapa komposisi lagu sehingga tidak monoton dan membosankan. Pemahaman pentingnya manajemen terbuka dalam sebuah kelompok juga didapatkan dari penyuluhan ini.

\section{SIMPULAN}

Seperti yang telah disampaikan sebelumnya bahwa sasaran utama dari penyuluhan dan kepelatihan seni Gejoglesung ini, khususnya diberikan kepada anggota dan pengurus seni Gejoglesung "Kumandhang", di Karanganom I, Ngawis Karangmojo Gunungkidul. Diharapkan ke depannya dapat menarik minat generasi muda pada usia remaja untuk menjadi pewaris kesenian rakyat yang ada. Hal tersebut sangat selaras dengan tujuan pemerintah Kabupaten Gunungkidul khususnya Dinas Kebudayaan yang ditindak lanjuti oleh pemerintah Daerah Istimewa Yogyakarta, dengan disetujuinya keistimewaan oleh pemerintah pusat. 
Dengan adanya penyuluhan ini diharapkan tidak terjadi kesenjangan dengan generasi sebelumnya yang pada akhirnya seni Gejoglesung "Kumandhang", tersebut tidak mengalami kepunahan.

Berdasarkan pengamatan setelah dilaksanakan penyuluhan seni selama 10 kali pertemuan yang di akhiri dengan pementasan, seluruh peserta penyuluhan ternyata mempunyai kemampuan ketrampilan dan wawasan yang cukup signifikan sesuai dengan tujuan yang ingin dicapai. Walaupun kedisiplinan untuk kedatangan berlatih terkadang tidak pernah tepat waktu, namun ketekunan dalam berlatih cukup tinggi. Hal ini menjadikan motivasi tersendiri bagi dosen penyuluh untuk menanamkan kesadaran tentang kedisiplinan. Peserta penuluhan secara prinsip mempunyai bakat dan minat yang luarbiasa terhadap kesenian Gejoglesung. Hal tersebut apabila ditempa secara berkelanjutan niscaya akan menjadi seniman tradisional yang cukup mumpuni.

\section{SARAN}

Program-program dari LPM ISI Yogyakarta memang senantiasa berupaya meningkatkan kemampuan masyarakat berdasarkan potensi yang telah ada. Beberapa unsur yang sangat perlu dalam pelaksanan tersebut yakni adanya sinergi antara LPM ISI Yogyakarta dan masyarakat yang menjadi sasaran penyuluhan. Kemauan, semangat, dan kemampuan dalam proses pembinaan, menjadi dasar tercapainya tujuan dari program tersebut. Peningkatan kemampuan berdasarkan potensi yang ada dengan diadakannya penyuluhan tersebut masih perlu dilanjutkan untuk mencapai target kelompok seni tersebut mampu menyajikan dan berkreasi secara mandiri. Untuk itu pelaksanaan program penyuluhan Seni di suatu tempat yang memang mempunyai prospek untuk lebih maju, seyogyanya tidak hanya satu kali pelaksanaan namun perlu berkelanjutan.

\section{UCAPAN TERIMA KASIH}

Ucapan terima kasih disampaikan kepada: LPM ISI Yogyakara yang telah memberikan kesempatan untuk melakukan penyuluhan seni dengan memberikan dukungan fasilitas dan dana untuk terselenggaranya penyuluhan; Pengurus dan Anggota dari Grup Gejoglesung "Kumandhang" khususnya, dan masyarakat Dusun Karanganom IDrsa Ngawis-Kecamatan KarangmojoKabupaten Gunungkidul.

\section{DAFTAR PUSTAKA}

Nagara, M. M. C., \& Machfauzia, A. N. (2020). The Meaning of Qualisign, Sinsign, and Legisign of Gejog Lesung Art "Mukti Lestari" in Sewon Bantul. https://doi.org/10.2991/assehr.k. 200703.034

Rukmana, I., Murdiono, M., \& Fenditasari, K. (2020). Utilizing Students' Critical Thinking Skill On Undang-Undang Dasar 1945 Through Android (Gejog Lesung) Based-E-Learning Media. https://doi.org/10.4108/eai.2-112019.2294721 
Suprapto, W., \& Kariadi, D. (2018). Pelatihan Gejog Lesung pada Pemuda Dusun Gunturan, Triharjo, Pandak, Bantul Sebagai Upaya Pelestarian Budaya Bangsa. Jurnal ABDINUS : Jurnal Pengabdian Nusantara. https://doi.org/10.29407/ja.v2i1. 11888

Supriyadi. (2017). Keberadaan Seni Gejog Lesung Mukti Lestari di Desa Pendowoharjo Bantul Yogyakarta. SELONDING.

https://doi.org/10.24821/selondi ng.v12i12.2932 